This article is licensed under the Creative Commons Attribution-NonCommercial 4.0 International License (CC BY-NC) (http://www.karger.com/Services/OpenAccessLicense). Usage and distribution for commercial purposes requires written permission.

\title{
Radiotherapy Late Effects and Osteogenesis Imperfecta: Dos and Don'ts in Clinical Practice
}

\author{
Joyce E. Lodeweges ${ }^{a} \quad$ Fleur S. van Dijk ${ }^{b, c}$ Joost J.C. Verhoeff
}

aDepartment of Radiotherapy, University Medical Center Utrecht, Utrecht, The Netherlands; ${ }^{b}$ North West Thames Regional Genetics Service, Ehlers-Danlos Syndrome National Diagnostic Service London, North West Health Care University NHS Trust, Harrow, UK; ' ${ }^{C}$ xpert Center for Adults with Osteogenesis Imperfecta, Isala Hospital, Zwolle, The Netherlands

\section{Keywords}

Radiotherapy · Osteogenesis imperfecta · Toxicity

\section{Abstract}

In radiation oncology, little is known about possible difficulties in patients with Osteogenesis Imperfecta (OI). Because radiotherapy can cause various side-effects including bone, soft tissue and cardiovascular toxicities, we foresee that patients with OI may experience even more acute and late side-effects due to pre-existing problems. We present two cases of radiotherapy in patients with $\mathrm{Ol}$, measured the effects of radiation on their bone mineral density and provide clinical recommendations for patient tailored radiotherapy strategies in patients with OI.

(C) 2019 The Author(s)

Published by S. Karger AG, Basel 


\section{Case Reports in Oncology}

Case Rep Oncol 2019;12:322-331

DOI: $10.1159 / 000499903$

(C) 2019 The Author(s). Published by S. Karger AG, Basel www.karger.com/cro

Lodeweges et al.: Radiotherapy Late Effects and Osteogenesis Imperfecta

\section{Introduction}

In radiation oncology, little is described about possible malevolent interactions in patients with the rare genetic collagen disorder Osteogenesis Imperfecta (OI). In regular patients, depending on the treatment site, radiotherapy can cause various side-effects including bone, soft tissue and cardiovascular toxicities. We therefore hypothesize that if patients with OI, who to a greater or lesser extent already have pre-existing bone, soft tissue and/or cardiovascular problems, undergo radiotherapy, they may experience even more acute and late side-effects. In this article we present two cases of patients with OI who have been irradiated as examples of clinical cases to provide guidance on how to care for this rare group of patients regarding adjustments in radiation therapy management.

\section{Osteogenesis Imperfecta}

Based on the prevalence of osteogenesis imperfecta (OI), approximately 1 in 20.000 patients referred to radiotherapy centers has OI, or "brittle bone disease" [1]. The primary characteristic of $\mathrm{OI}$ is susceptibility to bone fractures with severity ranging from "slightly increased fracture frequency" to "multiple intra-uterine fractures and prenatal" or "perinatal death" [2]. OI has been divided in 5 different types (type 1-5) based on clinical and radiological features, with OI type 1 being the mildest and most common type of OI also known as classic non-deforming OI with blue sclerae as typical phenotype; type 2 is perinatally lethal OI; type 3 , progressively deforming OI; type 4, common variable OI with normal sclerae, and type 5 is characterized by among others interosseous calcification and/or hypertrophic callus [3]. In about $90 \%$ of cases, OI is caused by autosomal dominant mutations in the COL1A1 and COL1A2 genes. Dominant mutations lead to decreased and/or abnormal production of type 1 collagen. The remaining $10 \%$ of cases is due to other genetic causes of whom many are recessively inherited [4]. As type 1 collagen is abundantly present in bone, tendon, ligament, skin and sclerae, a reduced and/or abnormal collagen type 1 production may lead to a variety of clinical and radiological features in these patients. These include susceptibility to fractures with or without decreased bone mineral density (BMD); wormian bones (extra bone pieces within cranial sutures); short stature, bone deformities, blue/grey sclerae; opalescent teeth that wear quickly (dentinogenesis imperfecta); hearing loss, and joint hypermobility; cardiovascular complications such as valvular dysfunction and aortic root dilatation have also been reported [2].

\section{Individual 1}

Individual 1, is a 54-year-old patient with stage IV non-small cell lung cancer and cerebral metastases. He has OI type 1 (classic non-deforming OI with blue sclerae), which was diagnosed early because of a fractured clavicle at birth and confirmed with DNA analysis (c.588 + $5 \mathrm{G}>\mathrm{A}$ pathogenic variant in the COL1A1 gene). The clinical manifestations consisted of multiple fractures of the pelvis and the long bones (more than 10 since childhood), the presence of blue sclerae and dentinogenesis imperfecta. The most recent DEXA scan showed low BMD 
with a T-score of -2.3 for the lumbar spine and a T-score of -3.5 for the left hip. There was a positive family history with his mother and sibling being affected with OI type 1 as well.

The patient was diagnosed with cT3N2M1c non-small cell lung cancer with ipsilateral and mediastinal lymph nodes and multiple brain metastases after analysis for headache, dysarthria, apraxia and memory loss. Because of the relatively young age of the patient and absence of extracranial metastases, the multidisciplinary tumor board decided to treat the brain metastases with stereotactic radiotherapy for a long-lasting effect, but with a palliative intent.

Depending on the volume of the metastases, a stereotactic dose of $1 \times 18 \mathrm{~Gy}, 1 \times 21 \mathrm{~Gy}$ or $1 \times 24$ Gy was prescribed for five metastases using Volumetric Modulated Arc Therapy (VMAT) with three $6 \mathrm{MeV}$ photon Flattening Filter Free (FFF) beams. In this example, the adjacent skull received a mean dose of 7 Gy without special dose planning restrictions on the skull (Fig. 1).

Because of the high complications risk, due to chest deformities that may cause respiratory problems, cervical fragility that may lead to difficulties during intubation and due to possible hyperthermia caused by anesthesia, surgery for the lung tumor was not recommended. The patient was therefore referred for sequential radiotherapy. A dose of $25 \times 2.6$ Gy was prescribed to the lung tumor and the hilar and mediastinal lymph nodes, using one $10 \mathrm{MeV}$ photon VMAT arc. No extra radiotherapy dose planning constraints for the bone of the chest or other tissue types were prescribed.

During and after brain irradiation and lung radiotherapy, the patient did not experience any extra acute side effects or difficulties regarding $\mathrm{OI}$.

\section{Individual 2}

Individual 2 is a 46-year-old patient with osteogenesis imperfecta, who was diagnosed clinically with OI type 3 or 4 at the age of 1 year. This diagnosis has not been confirmed with DNA analysis. She sustained multiple fractures for which she underwent multiple surgical procedures including osteotomies. Because of extensive bone deformities, she has been wheelchair-bound since childhood. The most recent DEXA scan showed low BMD of the lumbar spine with a T-score of -6.0. In addition to the bone fractures, this patient is also under surveillance of the cardiologist because of a mildly dilated ascending aorta and aortic root of $38 \mathrm{~mm}$.

At the age of 12, the patient experienced painful swelling of his left femur due to hyperplastic callus formation after a femoral fracture. To slow down and eventually resorb the callus formation, the patient was referred for radiotherapy. The left femur received a prescribed dose of $5 \times 4 \mathrm{~Gy}$, using anterior posterior-posterior-anterior (AP-PA) fields of $6 \mathrm{MeV}$ photons to the whole left femur. Shortly after the treatment, the swelling and pain in the left femur decreased.

Twenty-three years later, at the age of 35 years, the patient was again referred to the radiotherapy department, now because of pain due to callus formation of the medial side of the right femur. A dose of $5 \times 4$ Gy was prescribed to the right femur using an AP-PA field of 10 $\mathrm{MeV}$ photons (Fig. 2). During and after the treatment no acute side effects were noticed and again the pain and swelling responded very well to the radiotherapy. 


\section{Case Reports in Oncology}

Case Rep Oncol 2019;12:322-331

DOI: $10.1159 / 000499903$

(C) 2019 The Author(s). Published by S. Karger AG, Basel www.karger.com/cro

Lodeweges et al.: Radiotherapy Late Effects and Osteogenesis Imperfecta

At age of 59, the patient was again referred to the radiotherapy department because of recurrent pain of his right femur. A radiotherapy planning-CT was conducted, but because of the mild character of the pain, and after shared decision making with the patient, radiation therapy was eventually not performed.

\section{Bone Mineral Density Changes due to Radiotherapy}

We aimed to measure effects of radiotherapy on BMD of the 2 patients in skull and femur. Although the gold standard for measuring BMD is the DEXA scan, several reports show Hounsfield Units (HU) derived from CT scans to be an accurate estimate for BMD [5]. To put findings in perspective, mean $\mathrm{HU}$ of ten occipital skulls and ten right femora of healthy patients of matching age were assessed.

Comparison in mean $\mathrm{HU}$ of exactly matched areas of bones of our patients could be made prior and post radiotherapy, using the radiotherapy planning-CT scans that were conducted sequentially in both patients. In individual 1 , mean $\mathrm{HU}$ were measured in the high dose $(1 \times$ $7 \mathrm{~Gy}$ ) area of the adjacent skull to the occipital brain metastasis (Fig. 1). In individual 2, mean HU were measured in the target area of the right femur (Fig. 2) and in a non-irradiated area of the right femur. See Table 1 for the results.

\section{Discussion}

Osteogenesis imperfecta (OI) is an inherited connective tissue disorder which is characterized primarily by fractures, but soft tissue complications and cardiovascular problems have also been reported [3,4]. As these clinical features are also seen as a late side-effect of radiotherapy, we hypothesized that radiotherapy in patients with OI might worsen their already existing problems such as decreased BMD. To our knowledge, only one case of radiotherapy in a patient with osteogenesis imperfecta has been reported previously [6]. However, no clear recommendations regarding radiotherapy in this group of patients were made. Here, we described two individuals with OI type 1 and a clinical diagnosis of OI type 3/4 that underwent radiotherapy for brain metastases of lung cancer and to decrease callus formation in the femora after femoral fractures.

Radiotherapy to normal, non-malignant bone tissue, such as the lumbar spine in abdominal radiotherapy, will lead to a decrease in BMD. This is a non-stochastic effect that does not have a threshold [7]. However, there is no mentioning in the literature about possible effects of radiotherapy on BMD in already osteopenic bone, as is often the case in OI. With radiotherapy effects on normal bone in mind, we state that the dose to the bony structures should be kept As Low as Reasonably Achievable (ALARA) in OI patients. In this case report, we measured the mean HU-values of the irradiated and non-irradiated bone structures to estimate the possible degree of BMD change. As stated before, several reports show profit of HU-values derived from CT scans to estimate the BMD [5]. However, all these studies used HU of trabecular bone of the lumbar spine. Therefore, we cannot extrapolate our $\mathrm{HU}$ findings to these data. In individual 1, the skull HU-value after 9 months for the bone tissue in the high dose area was the same as mean $\mathrm{HU}$ in ten healthy patients of matched age, who showed a standard deviation 


\section{Case Reports in Oncology}

Case Rep Oncol 2019;12:322-331

DOI: $10.1159 / 000499903$

(C) 2019 The Author(s). Published by S. Karger AG, Base www.karger.com/cro

Lodeweges et al.: Radiotherapy Late Effects and Osteogenesis Imperfecta

of 204, indicating a great variety in BMD of the occipital skull. In individual 2, the mean femoral HU prior to treatment (52) was much lower than the mean HU of the 10 healthy matched controls (475). The observed reduction in femoral HU-value after 4 years for the irradiated bone was larger than the reduction in HU-value for the non-irradiated bone (22 points reduction versus 5 points reduction) but within the standard deviation.

Patients with OI can suffer from cardiovascular problems such as valvular dysfunction and aortic root dilatation. The extent of aortic root dilatation is often mild but can be more pronounced in patients with OI type 3 , as seen in individual 2 . Aortic dissection is rare but has been reported in patients with OI [8]. Higher radiotherapy dose to the heart is correlated with decreased survival in lung cancer patients [9]. Also, mediastinal radiotherapy in patients with Hodgkin's lymphoma is a risk factor for development of clinically significant valvular heart disease. With increasing dose from 30 to $40 \mathrm{~Gy}$, the risk of valvular dysfunction increased from factor 1.4 to 11.8. Therefore in patients with OI or other inherited connective tissue disorders in which cardiac structures are affected, we advise to lower the dose to heart (valves) and large vessels as much as possible, by using VMAT techniques or even proton beam treatment for selected cases. In addition, we advise to lower the dose to soft tissue and skin as much as possible, to minimize late soft tissue and skin problems due to radiation induced fibrosis [10].

As mentioned earlier, OI is a multisystemic disorder and people with OI can also have eye problems (including corneal thinning, myopia, scleral rupture, glaucoma, and retinal detachment), dental problems and hearing loss [3, 4]. Involvement of the eyes, ears (specifically the cochleae) or teeth in a radiation field may lead to retinal detachment, sensorineural hearing loss or dental damage, respectively [11-13]. Especially in patients with OI, keeping the dose to the eyes as low as possible is advised, as treatment of radiation induced retinal detachment provides an increased risk of scleral rupture. The same ALARA principles should be maintained for the cochlea and teeth in patients with OI to minimize further damage.

For all the above recommendations, the prognosis of the patient should always be kept in mind. Figure 3 shows an advice of "extra organ at risk" (OAR) delineations such as skin, soft tissue and bones for axillary radiotherapy in an OI patient with breast cancer.

In previous literature, the use of low dose radiotherapy in the treatment of heterotopic ossification due to traumatic fractures or joint arthroplasties is well described [14]. Interestingly, one case report from 1994 reported favorable effects of radiotherapy in 2 individuals with $\mathrm{OI}$ and "heterotopic ossification induced by hyperplastic callus formation caused by trauma or operation." The authors reported pain relief and reduction of hyperplastic callus after treatment with $10 \times 1$ and $6 \times 1 \mathrm{~Gy}$, respectively [15]. As this concerns patients with hyperplastic callus formation, which is a hallmark of OI type 5 , it may be that these patients as well as individual 2 actually have OI type 5 which was described in 2000 for the first time and the genetic defect was not reported until 2012. In patients with OI type 5, pain syndrome associated with chronic or subperiosteal bone formation is difficult to control and steroids, non-steroidal anti-inflammatory drugs or bisphosphonates do not seem to have any effect. Therefore, multiple fraction low dose radiotherapy can be considered. Table 2 summarizes the above recommendations. 


\section{Conclusion}

Based on the prevalence of osteogenesis imperfecta (OI), approximately 1 in 20,000 patients referred to radiotherapy centers has OI, or "brittle bone disease." Our case histories of the two individuals with OI underline the necessity of patient tailored radiotherapy strategies in patients with OI. Although due to small numbers no strong clinical evidence is present, we advise extra OAR contouring of bony structures, heart and large vessels and of other soft tissues, and to adapt radiotherapy planning (ALARA) and minimize possible late effects in this patient group with susceptibility to features as present as primary disease characteristics. For patients with pain due to callus formation, multiple fraction low dose radiotherapy can be considered. This advice may also be applicable to patients with other genetic connective tissue disorders in whom bone tissue and/or heart and large vessels and other soft tissues can be affected.

\section{Statement of Ethics}

Subjects have given their written informed consent to publish their case (including publication of images).

\section{Disclosure Statement}

The authors have no conflicts of interest to declare.

\section{Funding Sources}

Not applicable.

\section{Author Contributions}

JL drafted the work. FD and JV substantively revised it. All authors read and approved the final manuscript.

\section{References}

1 Forlino A, Marini JC. Osteogenesis imperfecta. Lancet. 2016 Apr;387(10028):1657-71.

2 Van Dijk FS, Sillence DO. Osteogenesis imperfecta: clinical diagnosis, nomenclature and severity assessment. Am J Med Genet A. 2014 Jun;164A(6):1470-81.

3 Sillence DO, Senn A, Danks DM. Genetic heterogeneity in osteogenesis imperfecta. J Med Genet. 1979 Apr;16(2):101-16.

4 van Dijk FS, Byers PH, Dalgleish R, Malfait F, Maugeri A, Rohrbach M, et al. EMQN best practice guidelines for the laboratory diagnosis of osteogenesis imperfecta. Eur J Hum Genet. 2012 Jan;20(1):11-9. 
5 Pickhardt PJ, Pooler BD, Lauder T, del Rio AM, Bruce RJ, Binkley N. Opportunistic screening for osteoporosis using abdominal computed tomography scans obtained for other indications. Ann Intern Med. 2013 Apr;158(8):588-95.

6 Ducournau A, Lagarde P, Henriques de Figueiredo B, Antoine M, Breton-Callu C, Petit A, et al. Radiothérapie chez une patiente atteinte d'un cancer du sein et d'ostéogenèse imparfaite: à propos d'un cas. Cancer Radiother. 2014 Mar;18(2):132-5.

7 Wei RL, Jung BC, Manzano W, Sehgal V, Klempner SJ, Lee SP, et al. Bone mineral density loss in thoracic and lumbar vertebrae following radiation for abdominal cancers. Radiother Oncol. 2016 Mar;118(3):430-6.

8 McNeeley MF, Dontchos BN, Laflamme MA, Hubka M, Sadro CT. Aortic dissection in osteogenesis imperfecta: case report and review of the literature. Emerg Radiol. 2012 Dec;19(6):553-6.

9 Johnson-Hart CN, Price GJ, Faivre-Finn C, Aznar MC, van Herk M. Residual setup errors towards the heart after image guidance linked with poorer survival in lung cancer patients: do we need stricter IGRT protocols? Int J Radiat Oncol Biol Phys. 2018 Oct;102(2):434-42.

10 Nguyen HQ, To NH, Zadigue P, Kerbrat S, De La Taille A, Le Gouvello S, et al. Ionizing radiation-induced cellular senescence promotes tissue fibrosis after radiotherapy. A review. Crit Rev Oncol Hematol. 2018 Sep;129:13-26.

11 Seregard S, Pelayes DE, Singh AD. Radiation therapy: posterior segment complications. Dev Ophthalmol. 2013;52:114-23.

12 Bhandare N, Jackson A, Eisbruch A, Pan CC, Flickinger JC, Antonelli P, et al. Radiation therapy and hearing loss. Int J Radiat Oncol Biol Phys. 2010 Mar;76(3 Suppl):S50-7.

13 Lieshout HF, Bots CP. The effect of radiotherapy on dental hard tissue-a systematic review. Clin Oral Investig. 2014 Jan;18(1):17-24.

14 Milakovic M, Popovic M, Raman S, Tsao M, Lam H, Chow E. Radiotherapy for the prophylaxis of heterotopic ossification: A systematic review and meta-analysis of randomized controlled trials. Radiother Oncol. 2015 Jul;116(1):4-9.

15 Micke 0, Wagner W, Pötter R, Prott FJ, Karbowski A. [The radiotherapy of hyperplastic heterotopic ossification in osteogenesis imperfecta. 2 case reports]. Strahlenther Onkol. 1994 Jun;170(6):347-51. 


\section{Case Reports in Oncology}
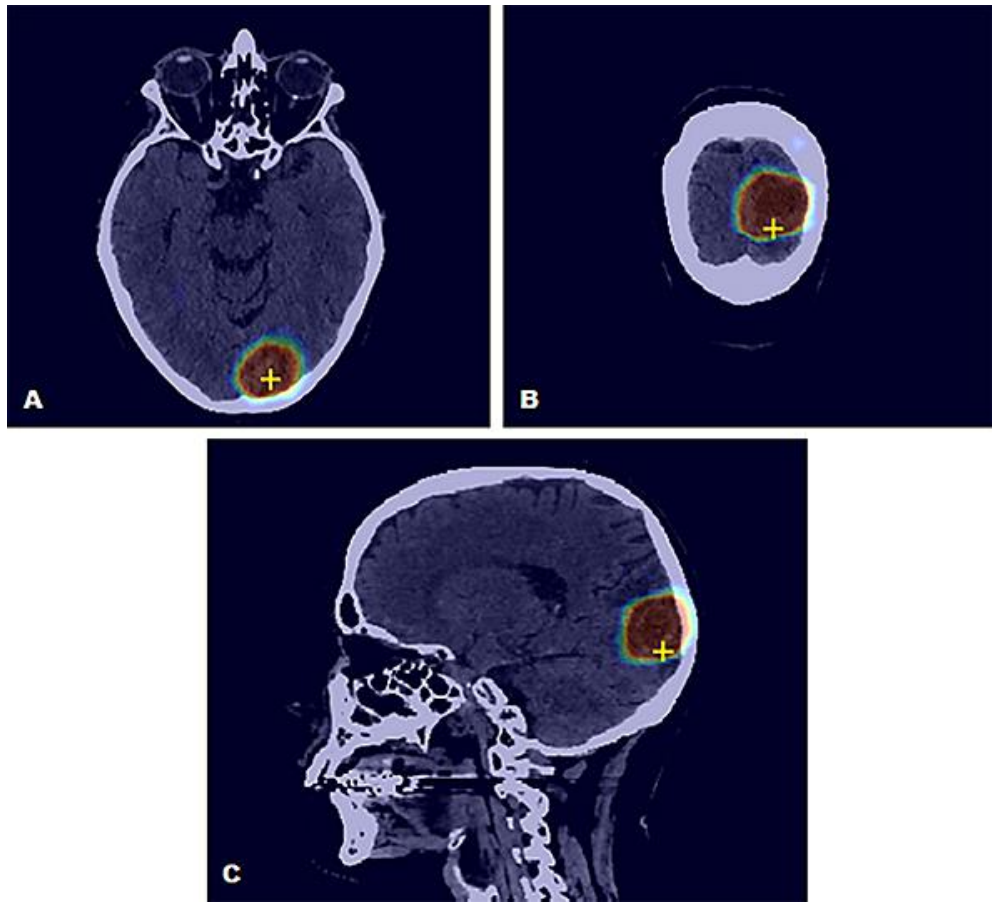

Fig. 1. Part of the dose distribution of the VMAT plan with three $6 \mathrm{MeV}$ photon FFF beams for an occipital metastasis (A. transversal view, B. coronal view, C. sagittal view). 


\section{Case Reports in Oncology}

Case Rep Oncol 2019;12:322-331

DOI: $10.1159 / 000499903$

(C) 2019 The Author(s). Published by S. Karger AG, Basel www.karger.com/cro

Lodeweges et al.: Radiotherapy Late Effects and Osteogenesis Imperfecta
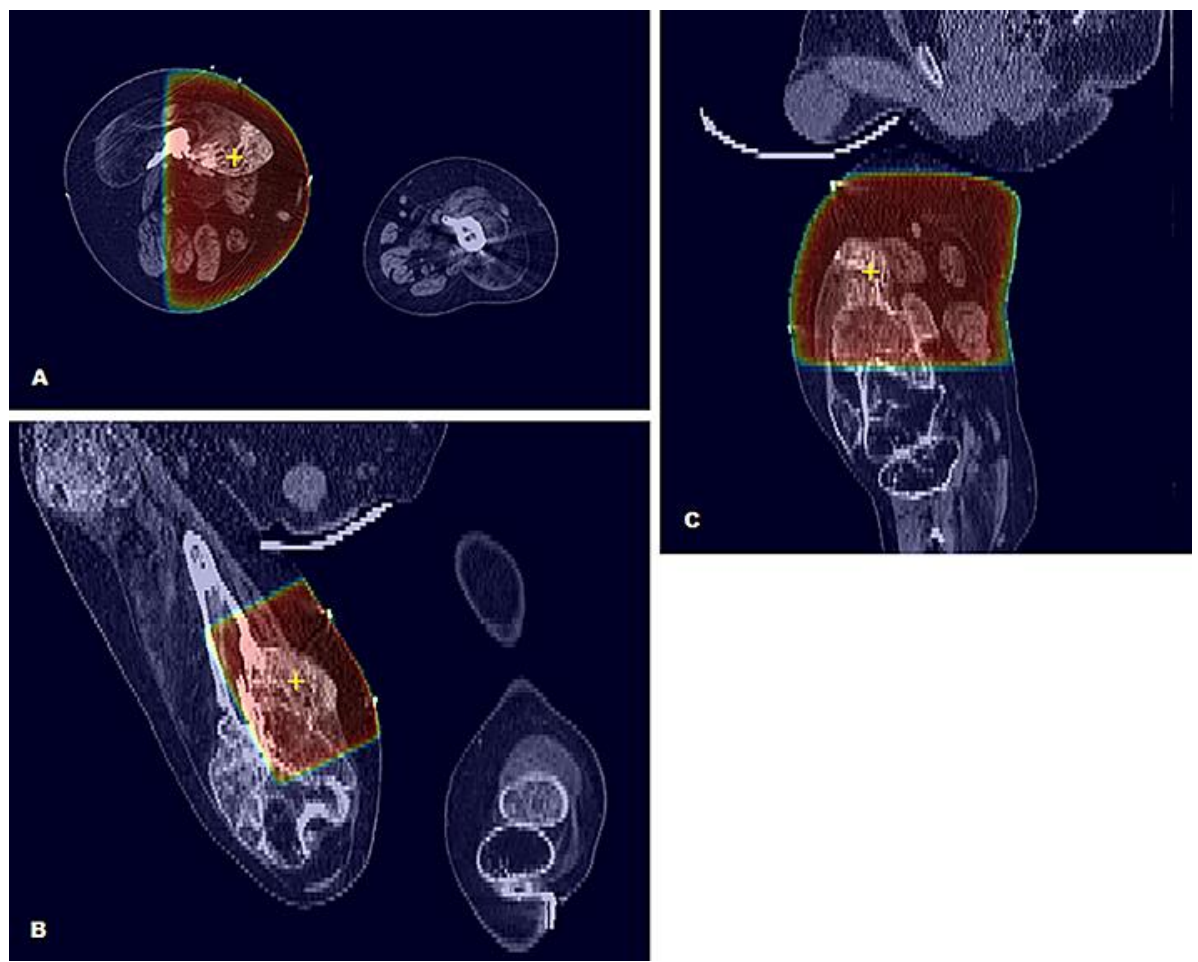

Fig. 2. Dose distribution of the AP-PA fields of $10 \mathrm{MeV}$ photons for treatment of callus formation in the right femur (A. transversal view, B. coronal view, C. sagittal view).

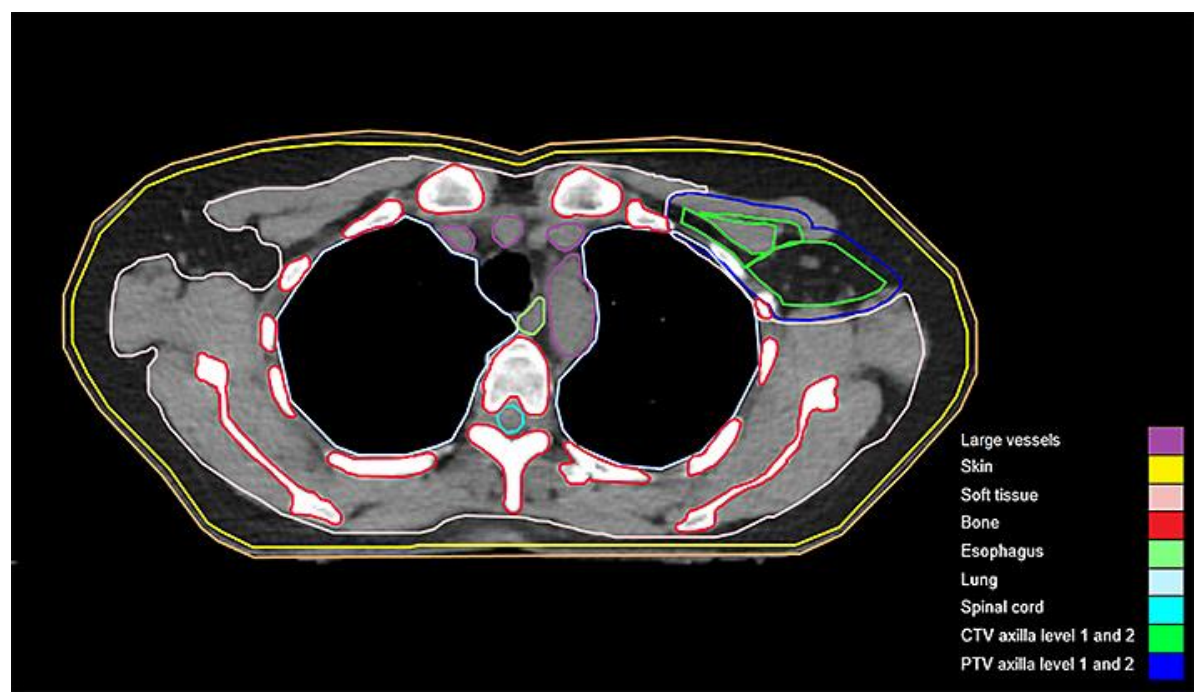

Fig. 3. Extra OAR delineations (large vessels, skin, soft tissue and bones) for axillary radiotherapy in case of an OI patient with left sided breast cancer. 
Table 1. Bone mineral density measurements

\begin{tabular}{lcc}
\hline & $\begin{array}{l}\text { BMD occipital skull } \\
\text { in mean HU (SD) }\end{array}$ & $\begin{array}{l}\text { BMD right femur } \\
\text { in mean HU (SD) }\end{array}$ \\
\hline $\begin{array}{l}\text { Individual 1 } \\
\quad \text { Pretreatment }\end{array}$ & $902(391)$ & - \\
$\quad$ Posttreatment (9 months later) & $997(385)$ & - \\
Individual 2 & - & $52(103)$ \\
$\quad$ Pretreatment high dose area & - & $30(70)$ \\
$\quad$ Posttreatment high dose area (4 years later) & - & $44(105)$ \\
$\quad$ Pretreatment non-irradiated area & - & $39(111)$ \\
$\quad$ Posttreatment non-irradiated area (4 years later) & $945(204)$ & $475(137)$ \\
Healthy patients $(n=10)$ & &
\end{tabular}

BMD, bone mineral density; HU, Hounsfield Units; SD, standard deviation.

Table 2. Recommendations for clinical practice

\section{Dos:}

1. Determine which clinical features of OI are present (contact an expert center for OI; https://www.orpha.net/)

2. Contour extra OARs depending on the site of radiation and which clinical features are present: bones, soft tissue, skin, heart valves, eyes (retina), ears (cochlea), teeth

3. Preferably use VMAT or proton therapy

4. Lower the dose to the OARs as much as possible (ALARA)

5. Consider multiple fraction low dose radiotherapy in patients with pain from callus formation

\section{Don'ts:}

1. Do not neglect the presence of OI

2. Do not bargain for a suboptimal (multimodality) treatment

3. Do not accept a suboptimal dose to Planning Target Volume (PTV)

4. Do not neglect acute and late side effects 